\title{
Lymphadenectomy in Management of Invasive Bladder Cancer
}

\author{
Ramy F. Youssef and Ganesh V. Raj \\ Department of Urology, UT Southwestern Medical Center at Dallas, J8-130 5323 Harry Hines Boulevard Dallas, \\ TX 75390-9110, USA \\ Correspondence should be addressed to Ganesh V. Raj, ganesh.raj@utsouthwestern.edu
}

Received 16 December 2010; Accepted 29 March 2011

Academic Editor: Vahit Ozmen

Copyright ( $) 2011$ R. F. Youssef and G. V. Raj. This is an open access article distributed under the Creative Commons Attribution License, which permits unrestricted use, distribution, and reproduction in any medium, provided the original work is properly cited.

\begin{abstract}
Radical cystectomy with pelvic lymphadenectomy represents the gold standard for treatment of muscle-invasive bladder cancer. Extent of the lymph node dissection and lymph node involvement during radical cystectomy are the most powerful prognostic factors associated with poor oncological outcome. However, the optimal boundaries of the lymph node dissection during a radical cystectomy are controversial. The published literature based mostly on retrospective studies suggests that increasing the number of nodes excised may have therapeutic and diagnostic benefits without significantly increasing the surgical morbidity. These conclusions are, however, influenced by selection and surgeon biases, inconsistencies in the quality of the surgery, and node count variability. In this paper, we establish the current understanding about the utility of lymphadenectomy during a radical cystectomy for muscle-invasive bladder cancer.
\end{abstract}

\section{Introduction}

Bladder cancer $(\mathrm{BC})$ is the seventh most prevalent cancer worldwide and results in significant morbidity and mortality. In the United States, $\mathrm{BC}$ is the fourth most common cancer in males and the ninth in females with an estimated 70,980 new cases and 14,330 deaths in 2009 [1]. Muscle-invasive $\mathrm{BC}$ (MIBC) accounts for virtually all the mortality from bladder cancer and represents more than a quarter $(\approx 25-$ $40 \%$ ) of all BC. MIBC spreads from the bladder in a predictable stepwise manner to the lymph nodes and then to visceral organs. Metastatic BC is incurable and invariably fatal. For patients with MIBC, radical cystectomy (RC) with pelvic lymphadenectomy (PLND) represents the mainstay of therapy. The PLND during RC represents both a chance to accurately stage the cancer as well as a chance to remove all the cancer from the body. An extended PLND may have prognostic and therapeutic benefits. However, there is still debate regarding the boundaries of adequate PLND during RC. In this paper, we will define the state of art regarding the extent of PLND and nodal prognostic factors and their effect on oncological outcomes of BC patients.

\section{Lymphatic Drainage of the Bladder}

The anatomy of lymphatic drainage of the urinary bladder is critically important for definition of the boundaries for an adequate PLND during RC. The bladder lymphatic drainage has well-defined origin from lymphatic plexus within its wall, in the submucosa and extending into the muscles. Lymphatic channels drain through anterior, lateral, and posterior intercalated lymph nodes (LNs) located within the perivesical fat. Efferent lymphatics then drain to the external iliac, obturator, internal iliac, and presacral LNs. Lymphatic trunks leading from the pelvic LNs subsequently drain into more proximal common iliac LNs and then to aortocaval LNs $[2,3]$. Skip lesions have been reported, but their rarity suggests that the pelvic LNs are the primary landing site and that metastasis occurs in an orderly progression $[2,4-8]$.

\section{Surgical Boundaries of the Lymphadenectomy}

Figure 1 shows the template of extended PLND during RC. Extended PLND include LNs between the aortic bifurcation 
and common iliac vessels (proximally), the genitofemoral nerve (laterally), the circumflex iliac vein and LN of Cloquet (distally), and the internal iliac vessels (posteriorly), including the obturator fossa and the presacral LNs anterior to the sacral promontory. An extended dissection may also extend superiorly to the level of the inferior mesenteric artery. Importantly, the PLND along the external iliac vessels is completely circumferential while the proximal dissection along the common iliac and great vessels includes anterior and lateral nodal tissues $[5,7,9]$. Standard PLND differs in its cranial boundary which is limited to the level of the common iliac bifurcation. A limited PLND involves the lymph nodes in the obturator fossa.

\section{Incidence of Lymph Node Metastasis}

The incidence of positive LNs in RC specimens is between $18-30 \%$ as shown in Table 1. Predictably, the incidence of LN involvement correlates with $\mathrm{T}$ stage, grade, and presence of lympho vascular invasion (LVI) $[5,10,11]$. Table 2 shows the correlation with stage in the largest $\mathrm{RC}$ series. The incidence of $\mathrm{LN}$ metastasis is $\leq 5 \%$ for $<\mathrm{T} 2$, around $25 \%$ in $\mathrm{T} 2$, and $40-45 \%$ in $\mathrm{T} 3 / \mathrm{T} 4 \mathrm{BC}$.

\section{Lymphadenectomy: Staging/Prognostic Benefits}

Precise staging of LN status is an important clinicopathological prognostic parameter following RC. Nodal involvement identifies a high-risk group that has the worst oncological outcomes and may benefit from adjuvant systemic therapies. Clearly, extending the field of PLND will increase the number of LNs removed and the chances of identifying positive nodes $[5,23,24,33]$. Vazina et al. found $16 \%$ patients with $\mathrm{T} 3 / \mathrm{T} 4$ disease to have $\mathrm{LN}$ metastasis proximal to the boundaries of standard PLND and $30 \%$ of patients with common iliac LN involvement also had involvement of presacral LNs [10]. Steven and Poulsen found $34.4 \%$ of positive LNs above the common iliac bifurcation [24]. An inadequately performed PLND may underestimate the true disease burden and underestimate the need for potentially therapeutic adjuvant therapies. An accurate PLND represents the best way to accurately stage patients with MIBC.

\section{Lymphadenectomy: Therapeutic Benefits}

Removal of involved lymph nodes theoretically can improve survival as it decreases overall tumor burden and allows the immune system and chemotherapeutics to target a smaller number of cancer cells, potentially with greater efficacy. Indeed, recent retrospective and prospective nonrandomized studies suggest a better oncological outcome from removing more LNs via an extended PLND during RC. Proponents for extended PLND note frequent involvement of nodes outside the standard PLND templates $[10,24,34]$. Some studies found more proximal LN metastases above the cranial boundary of the standard PLND $(\approx 20 \%)$ where common iliac, presacral, and LNs above the aortic bifurcation were involved in $15-23 \%, 6-8 \%$, and $4-10 \%$, respectively $[3,5]$. Additionally, up to $50 \%$ of patients with limited LN involvement can be rendered disease-free after extended PLND $[2,5]$. The benefits of PLND in removing micrometastatic disease appear to be significant in BC. Extended PLND requires an additional time but does not add significantly to the morbidity of the procedure [2, 35-37]. However, there are other studies that did not find an advantage for extended PLND $[6,7,11]$. The difference between these studies may reflect the selection criteria for the patients. Further, while the removal of grossly negative but microscopically involved LN may have a therapeutic benefit, the removal of bulky involved LN is unlikely to improve survival. The level of PLND remains controversial and can only be determined by well-designed carefully controlled prospective randomized studies.

\section{Therapeutic Benefits in Node Negative Bladder Cancer}

The extent of PLND may act as a surrogate marker for overall surgical quality and survival benefits from PLND in node negative patients during $\mathrm{RC}$ were reported $[13,15,31$, $38,39]$. A thorough extended PLND might decrease positive surgical margins, and, hence improve the oncological outcome. The 5-year RFS with organ-confined tumors was $85 \%$ with an extended dissection compared to $64 \%$ with similar pathology undergoing a more limited PLND [31]. We recommend an extended PLND, whenever possible; even in clinically node negative patients.

\section{Nodal Prognostic Factors}

The prognosis in patients with lymph node-positive disease can be stratified by the stage of the primary bladder tumor, extent of PLND, the number of lymph nodes removed, the number of LNs involved (tumor burden), LN density, and the presence of nodal extracapsular extension. We would like to highlight the most commonly studied nodal prognostic factors.

8.1. Number of Lymph Nodes Removed. The median nodal counts reported from RC series is considerably variable and ranges from 9 to 30 (Table 3 ). This number has been used as a surrogate marker for the adequacy of PLND. A standard PLND yields an average of 8-14 nodes while extending PLND up to the aortic bifurcation often yields 25-45 nodes $[2,31,34]$. Different studies suggested different cut point for the number of LNs that should be removed to achieve adequate PLND (Table 4). SEER data showed that PLND and the number of LNs removed are variable, and dissection of at least 10 to 14 nodes during $\mathrm{RC}$ is the most important prognostic factor [40]. The number of LNs removed not only suggests the completeness of the PLND, but may have prognostic significance in both LN positive and negative patients [3, 13]. Koppie et al. could not find a minimum number of LNs to be sufficient for optimal oncological 


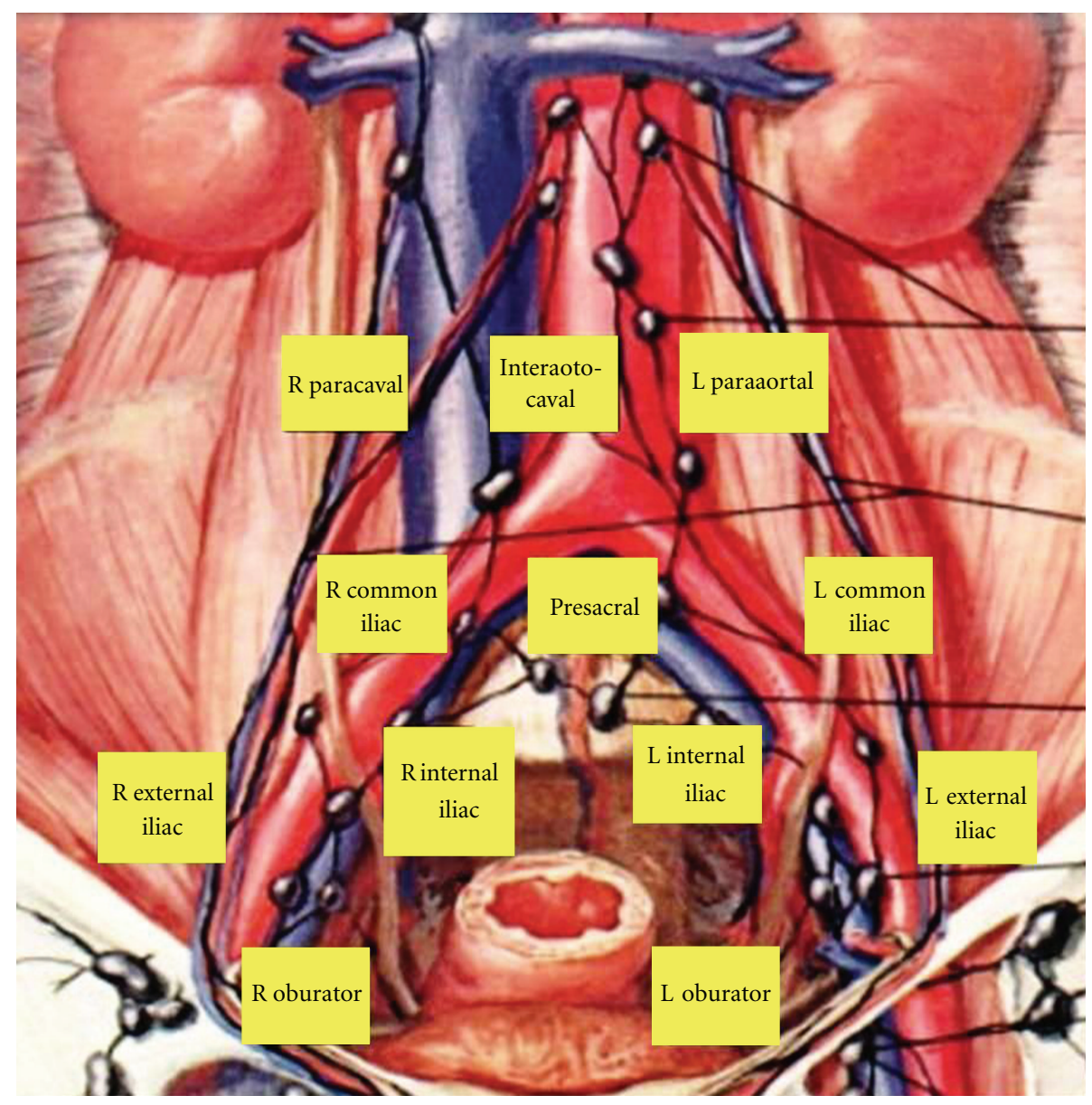

FIGURE 1: Template of extended lymph node dissection during radical cystectomy.

outcomes. Instead, the probability of survival continued to increase as the number of LNs removed increases [22].

Unfortunately, with the striking interinstitution and intrainstitution variability in node counts and variability within patients, it is hard to define an exact minimum number of LNs to be removed. The same extended PLND may yield 20 or $80 \mathrm{LN}$ depending on the patient, exposure to chemotherapy, surgical technique, institution at which performed, pathologist examining the LNs, and protocol used to evaluate LNs number. Thus, a cutoff of 30 would render the same extended PLND inadequate or adequate. We believe that the extent of PLND is more important marker for better surgical quality, and, finally, oncological outcome until pathologic processing and aforementioned variables can be addressed.

8.2. Lymph Node Yield. Many factors might explain the variability in node yield. Clinical, anatomical, pathological, surgical, and institutional factors may play a role $[2,4]$. Old age and associated comorbidities may hinder extended PLND [2, 52]. There might be some anatomic variability in the number of nodes present in different individuals [4]. Tumor stage may be associated with nodal yield [2, 4, 39]. On the other hand, negative margin status has been associated with higher nodal yield $[4,47]$. Recent BCG or neoadjuvant chemotherapy might have an effect, probably by causing inflammation and fibrosis thus helping more nodal yield [4]. Sending LNs in separate packages was reported to increase the nodal yield $[15,34]$. The method of pathologic evaluation including the use of fat-clearing solutions may play a role as well $[2,4]$. While there were contradictory reports about the effect of surgeon volume on $\mathrm{LN}$ yield $[4,47]$, academic or teaching hospitals with a higher RC volume tend to report higher LN counts [4, 47, 53]. Recently, Fang et al. implement a policy that at least $16 \mathrm{LNs}$ has to be examined pathologically. They showed that implementation of this policy can improve the survival due to increased awareness to perform a more thorough PLND [50].

8.3. Number of Positive Nodes (Tumor Burden). The number of positive LNs (tumor burden) is an important prognostic factor following $\mathrm{RC}[3,7,13,15,41]$. Recurrence and survival are inversely related to an increasing number of positive LNs. Some studies reported the absolute number of LNs involved as an independent prognostic factor. Others defined cutoff numbers for worse prognosis [40]. Herr et al. determined a cut-off of 4 positive LNs [39], Steven and Poulsen detrmined 5 positive LNS [24], and Stein 
TABLE 1: Incidence of lymph node metastasis in radical cystectomy.

\begin{tabular}{|c|c|c|c|c|}
\hline References & Year & No. of patients & No. of LN metastasis & (\%) of LN metastasis \\
\hline Vieweg et al. [12] & 1999 & 682 & 193 & 28.1 \\
\hline Leissner et al. [13] & 2000 & 447 & 136 & 30.4 \\
\hline Herr and Donat [14] & 2001 & 763 & 193 & 25.3 \\
\hline Stein et al. [15] & 2001 & 1,054 & 246 & 23.3 \\
\hline Gschwend et al. [16] & 2002 & 686 & 193 & 28.1 \\
\hline Madersbacher et al. [17] & 2003 & 507 & 121 & 23.9 \\
\hline Vazina et al. [10] & 2004 & 176 & 43 & 24.4 \\
\hline Leissner et al. [5] & 2004 & 290 & 81 & 27.9 \\
\hline Abdel-Latif et al. [11] & 2004 & 418 & 110 & 26.3 \\
\hline Nishiyama et al. [18] & 2004 & 1,113 & 162 & 14.6 \\
\hline Fleischmann et al. [19] & 2005 & 507 & 124 & 24.5 \\
\hline Hautmann et al. [20] & 2006 & 788 & 142 & 18.0 \\
\hline Shariat et al. [21] & 2006 & 833 & 198 & 23.8 \\
\hline Koppie et al. [22] & 2006 & 1,110 & 243 & 21.9 \\
\hline Stein et al. [23] & 2007 & 1,621 & 383 & 23.6 \\
\hline Steven and Poulsen [24] & 2007 & 336 & 64 & 19.0 \\
\hline Wright et al. [25] & 2007 & 5,201 & 1260 & 24.3 \\
\hline Ghoneim et al. [26] & 2008 & 2,720 & 555 & 20.4 \\
\hline Osawa et al. [27] & 2009 & 435 & 83 & 19.1 \\
\hline Bruins et al. [28] & 2009 & 1,600 & 369 & 23.1 \\
\hline Stephenson et al. [29] & 2010 & 763 & 178 & 23.3 \\
\hline Seiler et al. [30] & 2010 & 840 & 162 & 19.3 \\
\hline
\end{tabular}

TABLE 2: Correlation of pathological T stage with LN metastases.

\begin{tabular}{|c|c|c|c|c|c|c|c|c|c|}
\hline Study & $\begin{array}{l}\text { Poulsen } \\
\text { et al. [31] }\end{array}$ & $\begin{array}{l}\text { Viewg } \\
\text { et al. [12] }\end{array}$ & $\begin{array}{l}\text { Stein } \\
\text { et al. [15] }\end{array}$ & $\begin{array}{l}\text { Madersbacher } \\
\text { et al. [17] }\end{array}$ & $\begin{array}{l}\text { Leissner } \\
\text { et al. [5] }\end{array}$ & $\begin{array}{l}\text { Vazina } \\
\text { et al. [10] }\end{array}$ & $\begin{array}{l}\text { Abdel-Latif } \\
\text { et al. [11] }\end{array}$ & $\begin{array}{l}\text { Hautmann } \\
\text { et al. [20] }\end{array}$ & $\begin{array}{c}\text { Ghoneim } \\
\text { and } \\
\text { Abol-Enein } \\
{[32]}\end{array}$ \\
\hline Year & 1998 & 1999 & 2001 & 2003 & 2004 & 2004 & 2004 & 2006 & 2008 \\
\hline period & 1990-1997 & $\begin{array}{c}1980- \\
1990\end{array}$ & $\begin{array}{c}1971- \\
1997\end{array}$ & 1985-2000 & 1999-2002 & 1992-2002 & 1997-1999 & 1986-2003 & 1971-2000 \\
\hline $\begin{array}{l}\text { Total no. of } \\
\text { patients }\end{array}$ & 191 & 686 & 1054 & 507 & 290 & 176 & 418 & 788 & 2720 \\
\hline & \multicolumn{9}{|c|}{$\%$ of LN metastasis } \\
\hline $\begin{array}{l}\text { pT0, pTis, } \\
\text { and pT1 }\end{array}$ & 3 & 10 & 5 & 2 & 2 & 4 & 4 & 1 & 2 \\
\hline pT2a & 18 & 9 & 18 & 17 & 13 & 16 & 7 & 10 & 8 \\
\hline $\mathrm{T} 2 \mathrm{~b}$ & 25 & 23 & 27 & 34 & 22 & 40 & 25 & 41 & 19 \\
\hline pT3 & 51 & 43 & 45 & 41 & 44 & 50 & 48 & 44 & 39 \\
\hline pT4 & 44 & 41 & 45 & & 50 & & 65 & & 36 \\
\hline Total & 26 & 28 & 23 & 24 & 28 & 24 & 26 & 18 & 20 \\
\hline
\end{tabular}

et al. showed significantly worse survival in patients with $>8$ metastatic LNs [41]. Furthermore, the study from Mansoura showed a significance difference in prognosis when stratifying positive LNs ( 1 versus $2-5$ versus 5 ) [11]. This was also the case in a population-based study from the SEER database ( 1 versus 2 versus 3 versus $>3$ ) [25]. Collectively, It is obvious that larger tumor burden in LNs is associated with poor oncological outcomes. Further, bulky positive LNs are invariably associated with a poor prognosis [29].

\section{The Concept of "Lymph Node Density"}

The LN density could be a useful prognostic concept because it combines the extent of PLND as indicated by the total number of LNs removed and the tumor burden as indicated by the number of positive nodes. Herr and Stein were the first to introduce the concept of LN density (number of positive nodes/number of removed nodes) with a cutoff of $20 \%$ to stratify outcomes $[41,42]$. Table 5 describes the 
TABLE 3: Median number of lymph nodes removed in cystectomy series.

\begin{tabular}{lccc}
\hline References & Year & No. of patients & Median number of LNs removed (range) \\
\hline Stein et al. [41] & 2003 & 244 & $30(1-96)$ \\
Herr [42] & 2003 & 162 & $13(2-32)$ \\
Kassouf et al. [43] & 2006 & 108 & $12(1-58)$ \\
Kassouf et al. [44] & 2008 & 248 & $12(2-58)$ \\
Fleischmann et al. [45] & 2005 & 101 & $22(10-43)$ \\
Wright et al. [25] & 2008 & 1260 & $9(1-75)$ \\
Steven et al. [24] & 2007 & 64 & $27(11-49)$ \\
Abdel-Latif et al. [11] & 2004 & 110 & $18($ mean) \\
Lerner et al. [46] & 1993 & 302 & $31(3-96)$ \\
Leissner et al. [13] & 2000 & 268 & $15(1-46)$ \\
Herr et al. [47] & 2004 & 1042 & $10(0-54)$ \\
Koppie et al. [22] & 2006 & 117 & $9(0-53)$ \\
Poulsen et al. [31] & 1998 & 336 (Cleveland Clinic) & $25(9-67)$ extended \\
Dhar et al. [48] & 2008 & 322 (University of Bern) & $22(10-43)$ extended \\
\end{tabular}

TABLE 4: Suggested number of LNs to be removed to achieve better oncological outcomes.

\begin{tabular}{lcccc}
\hline References & Year & No. of patients & Median number of LNs removed (range) & Cut-off number of LNs to be removed \\
\hline Stein et al. [41] & 2003 & 244 & $30(1-96)$ & 15 \\
Konety et al. [49] & 2003 & 361 & N/A & $10-14$ \\
Herr [42] & 2003 & 162 & $13(2-32)$ & 13 \\
Kassouf et al. [44] & 2008 & 248 & $22(10-43)$ & 12 \\
Fleischmann et al. [45] & 2005 & 101 & $9(1-75)$ & 5 \\
Wright et al. [25] & 2008 & 1260 & $15(1-46)$ & 10 \\
Leissner et al. [13] & 2000 & 302 & $10(0-54)$ & 16 \\
Herr et al. [47] & 2004 & 268 & $8(0-44)$ for N0 & 10 \\
Herr et al. [39] & 2002 & 322 & $11(1-25)$ for N+ for N0 \\
& & & $17(0-53)$ & 11 for N+ \\
Fang et al. [50] & 2010 & 349 & $37(11-87)$ & 16 \\
Dangle et al. [33] & 2010 & 120 & 10 for N0 & $23-27$ \\
Shirotake et al. [51] & 2010 & 169 & 13 for N+ & 9 for N0
\end{tabular}

cut-off values suggested for LN density in different studies and the oncological outcomes based on these cut-off values. A pooled analysis of MD Anderson and Memorial SloanKettering Cancer Centers showed that LN density is superior to TNM nodal status in predicting oncological outcomes after RC [36]. Nevertheless, this index can be useful only if there is a standard number of nodes that have to be removed and a standard level of PLND. Certainly, a LN density of $20 \%$ based on 1 positive LN out of $5 \mathrm{LNs}$ removed is different than $20 \%$ based on 8 positive out of 40 LNs. Perhaps, this is the reason why there has not been widespread clinical use of this parameter since its introduction in 2003.

\section{Extracapsular Extension of Lymph Node Metastasis}

Extracapsular extension (perforation of the capsule of LN by tumor tissue with extranodal growth) has recently been shown to double the risk of recurrence when compared to intranodal confined LN metastasis. Fleischman et al. evaluated 101 patients who underwent RC and extended PLND for LN+ disease and analyzed the influence of extracapsular extension (found in 58\% of the patients) on patient prognoses. Patients with extracapsular extension had a significantly decreased recurrence free survival (RFS) (median, 12 versus 60 months, $P<$ .001 ) and overall survival (OS) (median, 16 versus 60 months, $P<.001)$ compared with those with intranodal metastases. Multivariate analyses confirmed that extracapsular extension of LN metastases was the strongest negative predictor for RFS [19]. However, others did not find a significant association between extracapsular extension and survival after RC, leading to issue of whether this pathological finding is really of importance [55]. 
TABLE 5: Cut-off lymph node densities and their effect upon oncological outcomes.

\begin{tabular}{|c|c|c|c|c|c|c|}
\hline \multirow{2}{*}{ References } & \multirow{2}{*}{ Year } & \multirow{2}{*}{ No. of patients } & \multirow{2}{*}{ Median number of LNs removed (range) } & \multirow{2}{*}{ Cut-off PLND } & \multicolumn{2}{|c|}{ 5-Y survival rates } \\
\hline & & & & & Below cut-off & Above cut-off \\
\hline Stein et al. [41] & 2003 & 244 & $30(1-96)$ & 20 & 17 & 44 \\
\hline Herr $[42]$ & 2003 & 162 & $13(2-32)$ & 20 & $8^{*}$ & $64^{*}$ \\
\hline Kassouf et al. [43] & 2006 & 108 & $12(1-58)$ & 25 & 11 & 38 \\
\hline Kassouf et al. [44] & 2008 & 248 & $12(2-58)$ & 20 & $15^{*}$ & $55^{*}$ \\
\hline Fleischmann et al. [45] & 2005 & 101 & $22(10-43)$ & 20 & 15 & 41 \\
\hline Steven and Poulsen [24] & 2007 & 64 & $27(11-49)$ & 20 & 25 & 47 \\
\hline Abdel-Latif et al. [11] & 2004 & 110 & 18 (mean) & 20 & 16 & 39 \\
\hline Wiesner et al. [54] & 2009 & 152 & $33(15-77)$ & 11 & $8^{*}$ & $34^{*}$ \\
\hline Osawa et al. [27] & 2009 & 435 & $12(1-80)$ & 25 & $12^{*}$ & $51^{*}$ \\
\hline
\end{tabular}

All studies reported RFS except * reported CSS.

\section{The Concept of "Sentinel Lymph Node"}

The sentinel node is defined as the initial site of lymphatic drainage from a primary tumor. Determination of sentinel node for $\mathrm{BC}$ should be on individualized basis rather than on anatomic location of primary tumor due to the variability of lymphatic drainage [4]. Ghoneim and AbolEnein introduced the concept of sentinel region (intrapelvic $\mathrm{LNs}$ ) rather than sentinel node $[6,7]$. Involvement of the intrapelvic LNs may be the first step in nodal metastasis in most BCs and skip lesions might be very rare [26, 47, 52, 55-57]. However, higher number of patients and longer followup is needed before widespread practice is accepted.

Recently, Studer group used multimodality technique to locate the primary lymphatic landing sites of the bladder. Their technique counted upon cystoscopic-guided injection of technetium nanocolloid followed by preoperative radioactive LN detection with SPECT/CT followed by intraoperative verification with gamma probe. They found that limited pelvic PLND removed only about $50 \%$ of all primary lymphatic landing sites while extending the PLND up to the ureteroiliac crossing removed 90\% [8]. Analysis of their study proves that the template or extent of PLND is more important than merely the number of LNs removed [58]. The concept of sentinel node remains investigational in BC. If sentinel nodes could be accurately identified on individual basis, this could guide the decision about the extent of PLND. Although, extended PLND can be safely and routinely performed with minimal additional morbidity, we do not currently see a need to compromise outcomes of patients with $\mathrm{BC}$ with a suboptimal nodal dissection and reliance on frozen section analyses.

\section{A Tailored Approach to Lymphadenectomy}

Tailoring PLND based on the clinical stage, so that patients with advanced tumors or evidence of nodal involvement would be treated with an extended PLND, whereas those with organ-confined disease and no evidence of nodal involvement would undergo standard PLND, has been advocated. However, the use of clinical stage of the primary tumor for determining of the extent of PLND is problematic
[38]. Understaging could happen in approximately half of patients with clinically organ-confined disease [38, 59]. Intraoperative finding including inspection and palpation of more proximal lymphatic regions may miss a substantial percentage of positive LNs [38]. If the morbidity of PLND is minimal, then there should be minimal downside to the use of an extended PLND in all patients. Currently, there are no reliable models to guide the decision regarding the extent of PLND.

\section{Morbidity of Lymphadenectomy}

Early complications of $28 \%$ and perioperative mortality rates of $2.6-3 \%$ have been reported in large RC series [ 15 , 26]. An extended PLND may prolong operative time by about 60 minutes. However, it does not appear to increase morbidity or mortality compared to the standard approach [2, 35-37]. Comparing LN positive versus LN negative cases, extended versus standard PLND confirmed that there are no significant differences in morbidity or mortality $[2,35-$ 37, 41]. Extended PLND is a safe option in experienced hands that may improve oncological outcomes by decreasing positive surgical margins and resection of undetected micrometastases $[36,38]$. Despite that the administration of neoadjuvant radiation or chemotherapy before $\mathrm{RC}$ may not increase the morbidity and mortality. Patients who have received these treatments should be judged carefully before performing an extended PLND, as there might be a higher risk of complications $[9,35,36]$.

\section{Laparoscopic-/Robotic-Assisted Surgery}

Laparoscopic-/robotic-assisted RC and PLND were reported as safe feasible procedures with acceptable nodal yield and potentially equivalent oncological outcomes to open RC with no added morbidities $[56,60]$. Complete removal of the LNbearing tissue up to aortic bifurcation or inferior mesenteric artery is more challenging using minimally invasive modalities. Recently, extended PLND has been demonstrated with the robotic system, with comparable LN yields [57, 61, 62].

We believe that without long-term functional and oncologic outcome data, laparoscopic- and robotic-assisted RC 
should be considered investigative techniques, and patients chosen for these modalities should be appropriately selected and counseled.

\section{Future Directions}

Many of the controversies regarding the extent and the utility of PLND in RC stem from the fact that data in support or against their use have been obtained from retrospective analyses of databases and trials. As such none of these studies were powered to answer the questions regarding the utility of PLND in RC. A multicenter prospective randomized clinical trial is in the final stages of approval by SWOG (PI: Seth Lerner, Baylor College of Medicine), and it randomizes patients to standard versus extended lymphadenectomy during $\mathrm{RC}$ for bladder cancer. The trial is powered to detect differences in survival and when completed may truly establish the role of PLND on the outcomes of patients with bladder cancer.

\section{Conclusions}

The incidence of nodal disease in BC is around 25\% and is influenced by other pathological factors, most importantly the pT stage. Extended PLND may provide prognostic and therapeutic advantages in both LN-positive and negative patients without significantly increasing morbidity. However, the extent of PLND during RC needs better definition through prospective randomized studies with long-term followup. Laparoscopic-/robotic-assisted RC and PLND are still new modalities that need longer evaluation before recommending for more patients.

\section{Abbreviations}

$\mathrm{BC}$ :

MIBC: $\quad$ Muscle-invasive bladder cancer

RC: $\quad$ Radical cystectomy

PLND: $\quad$ Pelvic lymph node dissection = lymphadenectomy

LN: $\quad$ Lymph node

LVI: $\quad$ Lymphovascular invasion

RFS: $\quad$ Recurrence-free survival

CSS: Cancer-specific survival

OS: Overall survival

SPECT/CT: Single-photon emission computed tomography.

\section{References}

[1] A. Jemal, R. Siegel, E. Ward, Y. Hao, J. Xu, and M. J. Thun, "Cancer statistics, 2009," CA Cancer Journal for Clinicians, vol. 59, no. 4, pp. 225-249, 2009.

[2] G. V. Raj and B. H. Bochner, "Radical cystectomy and lymphadenectomy for invasive bladder cancer: towards the evolution of an optimal surgical standard," Seminars in Oncology, vol. 34, no. 2, pp. 110-121, 2007.

[3] M. Buscarini, D. Y. Josephson, and J. P. Stein, "Lymphadenectomy in bladder cancer: a review," Urologia Internationalis, vol. 79, no. 3, pp. 191-199, 2007.
[4] S. Sharir and N. E. Fleshner, "Lymph node assessment and lymphadenectomy in bladder cancer," Journal of Surgical Oncology, vol. 99, no. 4, pp. 225-231, 2009.

[5] J. Leissner, M. A. Ghoneim, H. Abol-Enein et al., "Extended radical lymphadenectomy in patients with urothelial bladder cancer: results of a prospective multicenter study," Journal of Urology, vol. 171, no. 1, pp. 139-144, 2004.

[6] M. A. Ghoneim and H. Abol-Enein, "Lymphadenectomy with cystectomy: is it necessary and what is its extent?" European Urology, vol. 46, no. 4, pp. 457-461, 2004.

[7] H. Abol-Enein, M. El-Baz, M. A. Abd El-Hameed, M. AbdelLatif, and M. A. Ghoneim, "Lymph node involvement in patients with bladder cancer treated with radical cystectomy: a patho-anatomical study - a single center experience," Journal of Urology, vol. 172, no. 5 I, pp. 1818-1821, 2004.

[8] B. Roth, M. P. Wissmeyer, P. Zehnder et al., "A new multimodality technique accurately maps the primary lymphatic landing sites of the bladder," European Urology, vol. 57, no. 2, pp. 205-211, 2010.

[9] J. P. Stein, M. L. Quek, and D. G. Skinner, "Lymphadenectomy for invasive bladder cancer. II. Technical aspects and prognostic factors," British Journal of Urology International, vol. 97, no. 2, pp. 232-237, 2006.

[10] A. Vazina, D. Dugi, S. F. Shariat, J. Evans, R. Link, and S. P. Lerner, "Stage specific lymph node metastasis mapping in radical cystectomy specimens," Journal of Urology, vol. 171, no. 5, pp. 1830-1834, 2004.

[11] M. Abdel-Latif, H. Abol-Enein, M. El-Baz, and M. A. Ghoneim, "Nodal involvement in bladder cancer cases treated with radical cystectomy: incidence and prognosis," Journal of Urology, vol. 172, no. 1, pp. 85-89, 2004.

[12] J. Vieweg, J. E. Gschwend, H. W. Herr, and W. R. Fair, "Pelvic lymph node dissection can be curative in patients with node positive bladder cancer," Journal of Urology, vol. 161, no. 2, pp. 449-454, 1999.

[13] J. Leissner, R. Hohenfellner, J. W. Thüroff, and H. K. Wolf, "Lymphadenectomy in patients with transitional cell carcinoma of the urinary bladder; Significance for staging and prognosis," British Journal of Urology International, vol. 85, no. 7, pp. 817-823, 2000.

[14] H. W. Herr and S. M. Donat, "Outcome of patients with grossly node positive bladder cancer after pelvic lymph node dissection and radical cystectomy," Journal of Urology, vol. 165, no. 1, pp. 62-64, 2001.

[15] J. P. Stein, G. Lieskovsky, R. Cote et al., "Radical cystectomy in the treatment of invasive bladder cancer: long-term results in 1,054 patients," Journal of Clinical Oncology, vol. 19, no. 3, pp. 666-675, 2001.

[16] J. E. Gschwend, P. Dahm, and W. R. Fair, "Disease specific survival as endpoint of outcome for bladder cancer patients following radical cystectomy," European Urology, vol. 41, no. 4, pp. 440-448, 2002.

[17] S. Madersbacher, W. Hochreiter, F. Burkhard et al., "Radical cystectomy for bladder cancer today-a homogeneous series without neoadjuvant therapy," Journal of Clinical Oncology, vol. 21, no. 4, pp. 690-696, 2003.

[18] H. Nishiyama, T. Habuchi, J. Watanabe et al., "Clinical outcome of a large-scale multi-institutional retrospective study for locally advanced bladder cancer: a survey including 1131 patients treated during 1990-2000 in Japan," European Urology, vol. 45, no. 2, pp. 176-181, 2004.

[19] A. Fleischmann, G. N. Thalmann, R. Markwalder, and U. E. Studer, "Prognostic implications of extracapsular extension of pelvic lymph node metastases in urothelial carcinoma of the 
bladder," American Journal of Surgical Pathology, vol. 29, no. 1, pp. 89-95, 2005.

[20] R. E. Hautmann, J. E. Gschwend, R. C. de Petriconi, M. Kron, and B. G. Volkmer, "Cystectomy for transitional cell carcinoma of the bladder: results of a surgery only series in the neobladder era," Journal of Urology, vol. 176, no. 2, pp. 486492, 2006.

[21] S. F. Shariat, P. I. Karakiewicz, G. S. Palapattu et al., "Outcomes of radical cystectomy for transitional cell carcinoma of the bladder: a contemporary series from the Bladder Cancer Research Consortium," Journal of Urology, vol. 176, no. 6, pp. 2414-2422, 2006.

[22] T. M. Koppie, A. J. Vickers, K. Vora, G. Dalbagni, and B. H. Bochner, "Standardization of pelvic lymphadenectomy performed at radical cystectomy: can we establish a minimum number of lymph nodes that should be removed?" Cancer, vol. 107, no. 10, pp. 2368-2374, 2006.

[23] J. P. Stein, D. F. Penson, J. Cai et al., "Radical cystectomy with extended lymphadenectomy: evaluating separate package versus en bloc submission for node positive bladder cancer," Journal of Urology, vol. 177, no. 3, pp. 876-882, 2007.

[24] K. Steven and A. L. Poulsen, "Radical cystectomy and extended pelvic lymphadenectomy: survival of patients with lymph node metastasis above the bifurcation of the common iliac vessels treated with surgery only," Journal of Urology, vol. 178, no. 4, pp. 1218-1224, 2007.

[25] J. L. Wright, D. W. Lin, and M. P. Porter, "The association between extent of lymphadenectomy and survival among patients with lymph node metastases undergoing radical cystectomy," Cancer, vol. 112, no. 11, pp. 2401-2408, 2008.

[26] M. A. Ghoneim, M. Abdel-Latif, M. El-Mekresh et al., "Radical cystectomy for carcinoma of the bladder: 2,720 consecutive cases 5 years later," Journal of Urology, vol. 180, no. 1, pp. 121127, 2008.

[27] T. Osawa, T. Abe, N. Shinohara et al., "Role of lymph node density in predicting survival of patients with lymph node metastases after radical cystectomy: a multi-institutional study," International Journal of Urology, vol. 16, no. 3, pp. 274278, 2009.

[28] H. M. Bruins, G. J. Huang, J. Cai, D. G. Skinner, J. P. Stein, and D. F. Penson, "Clinical outcomes and recurrence predictors of lymph node positive urothelial cancer after cystectomy," Journal of Urology, vol. 182, no. 5, pp. 2182-2187, 2009.

[29] A. J. Stephenson, M. C. Gong, S. C. Campbell, A. F. Fergany, and D. E. Hansel, "Aggregate lymph node metastasis diameter and survival after radical cystectomy for invasive bladder cancer," Urology, vol. 75, no. 2, pp. 382-386, 2010.

[30] R. Seiler, M. Von Gunten, G. N. Thalmann, and A. Fleischmann, "Pelvic lymph nodes: distribution and nodal tumour burden of urothelial bladder cancer," Journal of Clinical Pathology, vol. 63, no. 6, pp. 504-507, 2010.

[31] A. L. Poulsen, T. Horn, and K. Steven, "Radical cystectomy: extending the limits of pelvic lymph node dissection improves survival for patients with bladder cancer confined to the bladder wall," The Journal of urology, vol. 160, no. 6, pp. 20152020, 1998.

[32] M. A. Ghoneim and H. Abol-Enein, "Management of muscleinvasive bladder cancer: an update," Nature Clinical Practice Urology, vol. 5, no. 9, pp. 501-508, 2008.

[33] P. P. Dangle, M. C. Gong, R. R. Bahnson, and K. S. Pohar, "How do commonly performed lymphadenectomy templates influence bladder cancer nodal stage?" Journal of Urology, vol. 183, no. 2, pp. 499-504, 2010.

[34] B. H. Bochner, D. Cho, H. W. Herr, M. Donat, M. W. Kattan, and G. Dalbagni, "Prospectively packaged lymph node dissections with radical cystectomy: evaluation of node count variability and node mapping," Journal of Urology, vol. 172, no. 4, part 1, pp. 1286-1290, 2004.

[35] JA. H. Ku, "Role of pelvic lymphadenectomy in the treatment of bladder cancer: a mini review," Korean Journal of Urology, vol. 51, no. 6, pp. 371-378, 2010.

[36] F. A. Yafi and W. Kassouf, "Role of lymphadenectomy for invasive bladder cancer," Journal of the Canadian Urological Association, vol. 3, no. 6, supplement 4, pp. S206-S210, 2009.

[37] C. Brössner, A. Pycha, A. Toth, C. Mian, and W. Kuber, "Does extended lymphadenectomy increase the morbidity of radical cystectomy?" British Journal of Urology International, vol. 93, no. 1, pp. 64-66, 2004.

[38] K. M. Sanderson, D. Skinner, and J. P. Stein, "The prognostic and staging value of lymph node dissection in the treatment of invasive bladder cancer," Nature Clinical Practice Urology, vol. 3, no. 9, pp. 485-494, 2006.

[39] H. W. Herr, B. H. Bochner, G. Dalbagni, S. M. Donat, V. E. Reuter, and D. F. Bajorin, "Impact of the number of lymph nodes retrieved on outcome in patients with muscle invasive bladder cancer," Journal of Urology, vol. 167, no. 3, pp. 12951298, 2002.

[40] B. R. Konety and S. A. Joslyn, "Factors influencing aggressive therapy for bladder cancer: an analysis of data from the SEER program," Journal of Urology, vol. 170, no. 5, pp. 1765-1771, 2003.

[41] J. P. Stein, J. Cai, S. Groshen, and D. G. Skinner, "Risk factors for patients with pelvic lymph node metastases following radical cystectomy with en bloc pelvic lymphadenectomy: the concept of lymph node density," Journal of Urology, vol. 170, no. 1, pp. 35-41, 2003.

[42] H. W. Herr, "Superiority of ratio based lymph node staging for bladder cancer," Journal of Urology, vol. 169, no. 3, pp. 943945, 2003.

[43] W. Kassouf, D. Leibovici, M. F. Munsell, C. P. Dinney, H. B. Grossman, and A. M. Kamat, "Evaluation of the relevance of lymph node density in a contemporary series of patients undergoing radical cystectomy," Journal of Urology, vol. 176, no. 1, pp. 53-57, 2006.

[44] W. Kassouf, P. K. Agarwal, H. W. Herr et al., "Lymph node density is superior to TNM nodal status in predicting diseasespecific survival after radical cystectomy for bladder cancer: analysis of pooled data from MDACC and MSKCC," Journal of Clinical Oncology, vol. 26, no. 1, pp. 121-126, 2008.

[45] A. Fleischmann, G. N. Thalmann, R. Markwalder, and U. E. Studer, "Extracapsular extension of pelvic lymph node metastases from urothelial carcinoma of the bladder is an independent prognostic factor," Journal of Clinical Oncology, vol. 23, no. 10, pp. 2358-2365, 2005.

[46] S. P. Lerner, D. G. Skinner, G. Lieskovsky et al., "The rationale for en bloc pelvic lymph node dissection for bladder cancer patients with nodal metastases: long-term results," Journal of Urology, vol. 149, no. 4, pp. 758-765, 1993.

[47] H. W. Herr, J. R. Faulkner, H. B. Grossman et al., "Surgical factors influence bladder cancer outcomes: a cooperative group report," Journal of Clinical Oncology, vol. 22, no. 14, pp. 2781-2789, 2004. 
[48] N. B. Dhar, E. A. Klein, A. M. Reuther, G. N. Thalmann, S. Madersbacher, and U. E. Studer, "Outcome after radical cystectomy with limited or extended pelvic lymph node dissection," Journal of Urology, vol. 179, no. 3, pp. 873-878, 2008.

[49] B. R. Konety, S. A. Joslyn, and M. A. O’Donnell, “Extent of pelvic lymphadenectomy and its impact on outcome in patients diagnosed with bladder cancer: analysis of data from the surveillance, epidemiology and end results program data base," Journal of Urology, vol. 169, no. 3, pp. 946-950, 2003.

[50] A. C. Fang, A. E. Ahmad, J. M. Whitson, L. D. Ferrell, P. R. Carroll, and B. R. Konety, "Effect of a minimum lymph node policy in radical cystectomy and pelvic lymphadenectomy on lymph node yields, lymph node positivity rates, lymph node density, and survivorship in patients with bladder cancer," Cancer, vol. 116, no. 8, pp. 1901-1908, 2010.

[51] S. Shirotake, E. Kikuchi, K. Matsumoto et al., "Role of pelvic lymph node dissection in lymph node-negative patients with invasive bladder cancer," Japanese Journal of Clinical Oncology, vol. 40, no. 3, pp. 247-251, 2009.

[52] W. C. Huang and B. H. Bochner, "Current status of establishing standards for lymphadenectomy in the treatment of bladder cancer," Current Opinion in Urology, vol. 15, no. 5, pp. 315-319, 2005.

[53] B. K. Hollenbeck, Z. Ye, S. L. Wong, J. E. Montie, and J. D. Birkmeyer, "Hospital lymph node counts and survival after radical cystectomy," Cancer, vol. 112, no. 4, pp. 806-812, 2008.

[54] C. Wiesner, A. Salzer, C. Thomas et al., "Cancer-specific survival after radical cystectomy and standardized extended lymphadenectomy for node-positive bladder cancer: prediction by lymph node positivity and density," British Journal of Urology International, vol. 104, no. 3, pp. 331-335, 2009.

[55] W. Kassouf, D. Leibovici, T. Luongo et al., "Relevance of extracapsular extension of pelvic lymph node metastases in patients with bladder cancer treated in the contemporary era," Cancer, vol. 107, no. 7, pp. 1491-1495, 2006.

[56] R. S. Pruthi and E. M. Wallen, "Robotic-assisted laparoscopic pelvic lymphadenectomy for bladder cancer: a surgical atlas," Journal of Laparoendoscopic and Advanced Surgical Techniques, vol. 19, no. 1, pp. 71-74, 2009.

[57] H. J. Lavery, H. J. Martinez-Suarez, and R. Abaza, "Robotic extended pelvic lymphadenectomy for bladder cancer with increased nodal yield," British Journal of Urology International. In press.

[58] H. W. Herr, "Extent of pelvic lymph node dissection during radical cystectomy: where and why!," European Urology, vol. 57, no. 2, pp. 212-213, 2010.

[59] S. F. Shariat, G. S. Palapattu, P. I. Karakiewicz et al., "Discrepancy between clinical and pathologic stage: impact on prognosis after radical cystectomy," European Urology, vol. 51, no. 1, pp. 137-151, 2007.

[60] R. Ghavamian and A. A. Hakimi, "Lymph node dissection for bladder cancer: the issue of extent and feasibility in the minimally invasive era," Expert Review of Anticancer Therapy, vol. 9, no. 12, pp. 1783-1792, 2009.

[61] A. Kasraeian, E. Barret, X. Cathelineau et al., "Robot-assisted laparoscopic cystoprostatectomy with extended pelvic lymphadenectomy, extracorporeal enterocystoplasty, and intracorporeal enterourethral anastomosis: initial montsouris experience," Journal of Endourology, vol. 24, no. 3, pp. 409$413,2010$.

[62] M. Woods, R. Thomas, R. Davis et al., "Robot-assisted extended pelvic lymphadenectomy," Journal of Endourology, vol. 22, no. 6, pp. 1297-1302, 2008. 


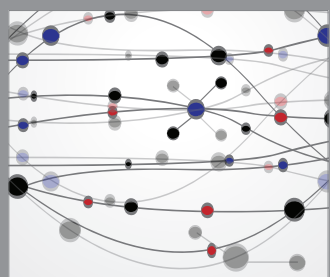

The Scientific World Journal
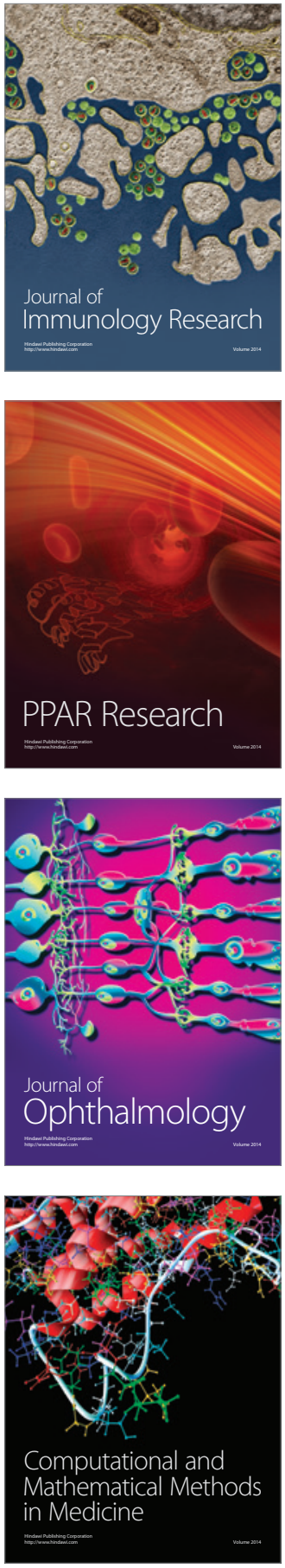

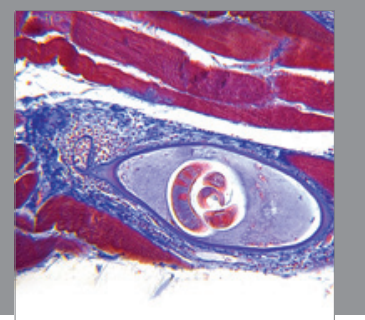

Gastroenterology

Research and Practice
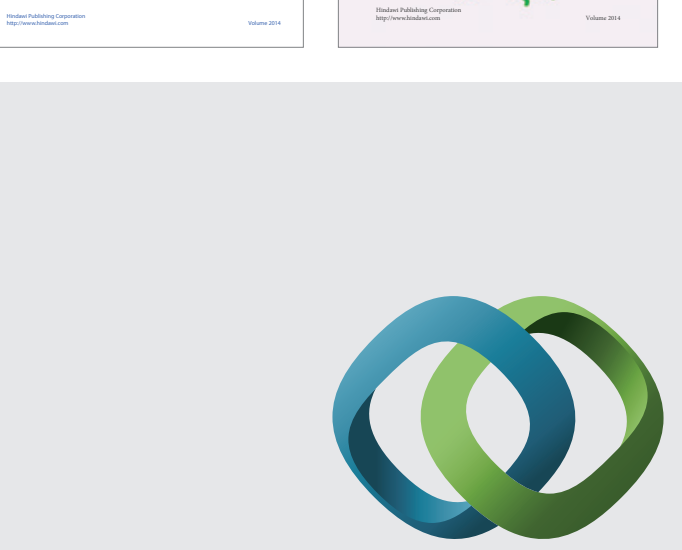

\section{Hindawi}

Submit your manuscripts at

http://www.hindawi.com
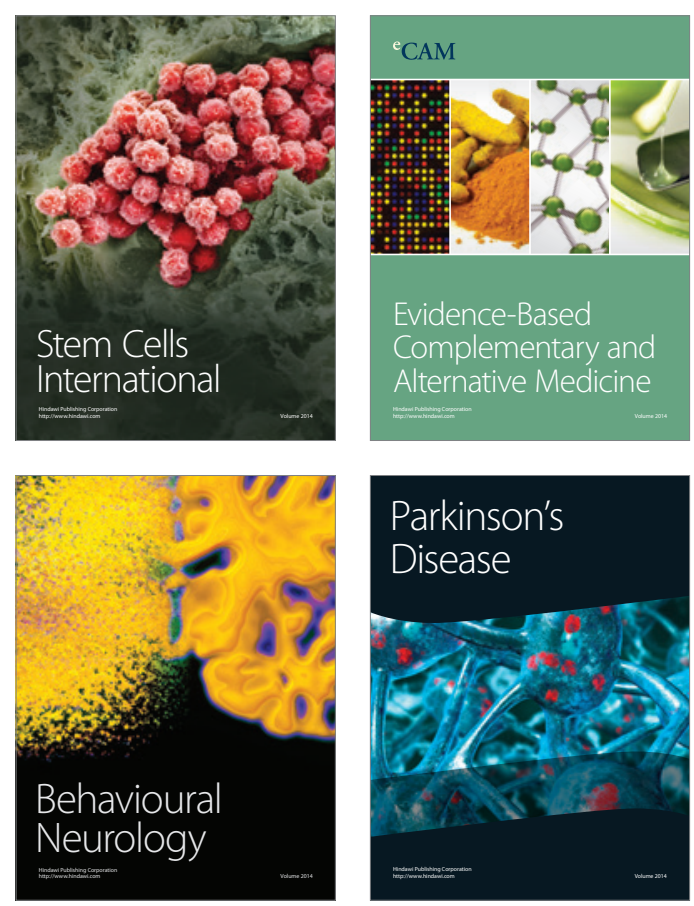

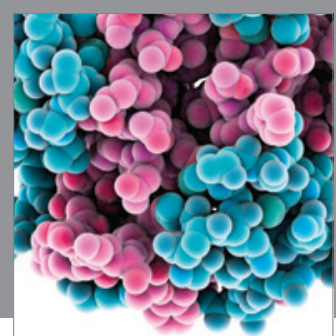

Journal of
Diabetes Research

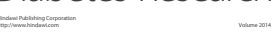

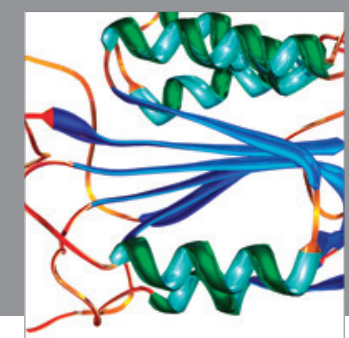

Disease Markers
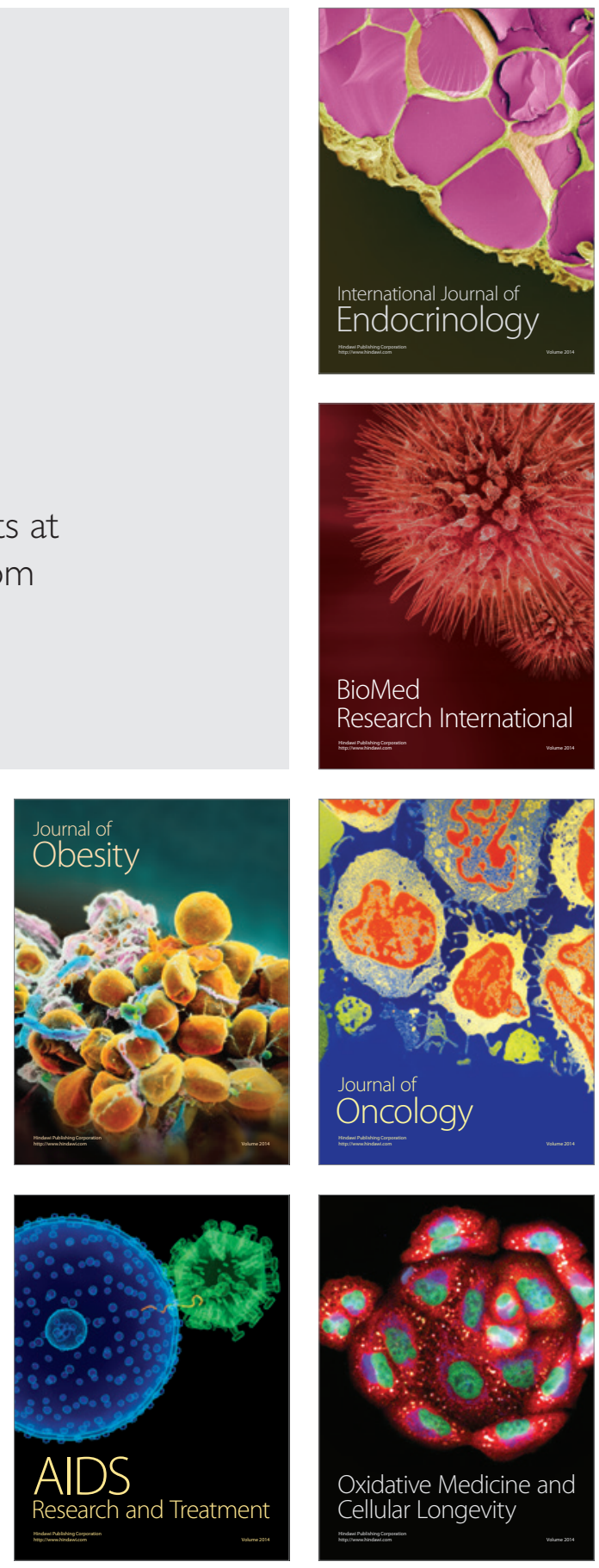